\title{
Simbolismo atacameño: un aporte etnológico a la comprensión de significados culturales
}

\author{
Maria Ester Grebe \\ Blas Hidalgo
}

\section{INTRODUCCIÓN}

A pesar del contacto cultural producido a través del prolongado proceso de hispanización -desde el siglo XVI al XX-, de los numerosos préstamos culturales adquiridos y de la pérdida gradual de la lengua kunza a lo largo del siglo XIX (CASAsSas, p. 19), los atacameños o likan-antai han conservado aún una parte importante de su cultura tradicional. Tanto en sus patrones cognitivo-simbólicos básicos de tiempo, espacio, movimiento, número y color, como del mito y sus reactualizaciones rituales, aparecen símbolos que mantienen vivos algunos de los significados culturales originales.

En la presente ponencia, se intenta contribuir con una identificación de estos símbolos e interpretación de sus significados a partir de las concepciones de los propios actores, con el fin de posibilitar la exploración de su potencialidad heurística en los marcos de la Antropología Social, Etnología y Arqueología atacameñas. Para ello, se estudia el simbolismo atacameño en sus diversos contextos socioculturales, destacándose su pertenencia e integración a patrones cognitivo-simbólicos tradicionales que constituyen núcleos básicos y esenciales de los sistemas ideacionales andinos. Dichos patrones parecen proporcionar continuidad y estabilidad culturales, a pesar de las transformaciones provocadas por el devenir histórico y el implacable flujo de los procesos de cambio sociocultural en marcha. En efecto, después de cuatro siglos de conquista y colonia estos patrones aún se mantienen (BASTIEN). Se les suele identificar como fenómenos concretos o abstractos característicos, detectados en diversas culturas del área andina, tanto vecinas como lejanas, con o sin afinidades e intercambios culturales. Sus símbolos asociados pueden sugerir el enunciado de hipótesis acerca de significados culturales del presente y pasado. En efecto, ellos permiten inferir - a partir de los datos empí- 
ricos del presente- proposiciones explicativas que pueden iluminar y dar sentido a los datos arqueológicos facilitando asi el aprovechamiento de los hallazgos etnográficos y su interpretación etnológica. Puesto que el arte y los símbolos andinos suelen generar modelos de representación que obedecen a una peculiar concepción del mundo, ambos pueden ser fuentes efectivas para una heurística etnológica y arqueológica.

En el curso del presente estudio entenderemos por símbolo una representación abstracta o concreta que reemplaza o sustituye a otra entidad o fenómeno. El símbolo se caracteriza por su polisemia (significados múltiples), su polarización de significados (polos semánticos ideológico-normativo versus sensorial), su capacidad de condensación y su unificación de significados aparentemente contradictorios (Turner, pp. 184-185). Posee ambigüedad y capacidad de transformaciones mûltiples, constituyendo matrices profundas de significado cultural. Se da en dos formas: metáfora, que se basa en asociaciones paradigmáticas consensuales pero arbitrarias; y metonimia, basada en relaciones de contigüidad (una parte que representa al todo) que generan cadenas sintagmáticas (LEACH, pp. 14-15).

Diversos trabajos etnográficos y etnológicos han contribuido al conocimiento exploratorio preliminar de la cultura atacameña. Entre ellos sobresalen los estudios de Mostny (1954 y 1967) y BartheL (1959), quienes aportan antecedentes significativos directos al tópico en estudio. En las décadas recientes, se observa una disminución ostensible de la productividad etnográfica y etnológica en el área atacameña, problema que sería necesario analizar oportunamente.

El presente estudio - que forma parte de un proyecto DTI, Universidad de Chile- es producto de un trabajo de campo intensivo desarrollado en el área atacameña durante el verano y mes de octubre de 1988. Los datos empíricos fueron recogidos principalmente en la aldea de Socaire, incluyéndose asimismo las aldeas y poblados de Camar, Talabre, Peine, Toconao, Caspana y ayllus de San Pedro, lo cual permitió tanto ensanchar el universo de estudio como también comparar y controlar la información recibida. En dichos lugares, se trabajó preferentemente con líderes y actores rituales reconocidos en sus respectivas comunidades por sus conocimientos tradicionales y/o calidad de especialistas. El trabajo de Socaire fue compartido por el alumno de Antropología en práctica Blas Hidalgo.

El enfoque metodológico empleado fue exploratorio, ciñéndose fundamentalmente a la etnografía tradicional adaptada y actualizada con recursos neoetnográficos que rescatan los puntos de vista del actor (SPRADley). Los datos recogidos en el verano de 1988 fueron controlados, ampliados y verificados en octubre del mismo año, con el registro etnográfico del rito de limpieza de canales de regadio en Socaire. El presente estudio es producto de un análisis de contenido y resumen de los resultados más sobresalientes de este trabajo etnográ- 
fico. Su primera versión fue presentada en el XI Congreso Nacional de Arqueología Chilena, Santiago, 1988.

I. Patrones Cognitivo-simbólicos del tiempo, espacio, movimiento, NÚMERO Y COLOR

\section{Tiempo}

La esencia de la concepción del tiempo atacameño es su circularidad, la cual es compartida con las respectivas concepciones de aymaras y mapuches de Chile (Grebe, 1987a y 1987b). El tiempo se representa simbólicamente como un gran círculo orientado contra las manecillas del reloj, en perpetua rotación, que sigue los movimientos del sol y de otros astros (véase Lám. I). Este círculo es dividido por un eje vertical imaginario que va del naciente al poniente (o entrante); y subdividido. por ciertas posiciones del sol y de astros nocturnos que sirven de indicadores de tiempo. Puesto que los antiguos lexemas en kunza se perdieron durante el siglo pasado, los atacameños han traducido algunos de ellos al español. Surge así una versión simplificada e hispanizada de la temporalidad atacameña, en la cual subsisten elementos andinos reconocibles, tales como la circularidad siguiendo el movimiento solar, la orientación hacia el Este, las connotaciones del día y ia noche, y el cómputo del tiempo centrado en las posiciones del sol y de ciertos astros nocturnos.

Se reconocen las siguientes posiciones del sol que subdividen el día: a) "cuando va aclarando el día" o "cuando va rayando el sol". correspondientes a distintos momentos del amanecer cuyos indicadores son el lucero grande de la mañana y el canto del gallo (antes de la salida del sol); b) naciente, que corresponde a la salida del sol en el Este; c) "cuando el sol está en el medio del mundo", que corresponde al mediodía y se reconoce porque los objetos no proyectan sombra; y d) entrante o "cuando el sol se entra", que corresponde a la puesta del sol en el poniente. Por tanto, "mirar el sol" es calcular el tiempo durante el día. Los antiguos atacameños solían enterrar un palo en el suelo, guiándose por las transformaciones de la sombra proyectada por éste para verificar la hora. A su vez, las posiciones de ciertos astros permiten el cómputo del tiempo durante la noche, reconociéndose: e) "cuando está oscureciendo", correspondiente al crepúsculo o atardecer, marcado por el surgimiento al poniente del lucero chico de la tarde; y f) medianoche, marcada por la posición alta de este mismo lucero. No obstante, el tiempo nocturno se calcula por las relaciones posicionales de los siguientes astros: los dos luceros aludidos, la cruz del sur, las tres Marías y las cabrillas. Entre éstas, se destaca la cruz del sur, cuya forma representa al suri (avestruz andino), calculándose las fases del tiempo nocturno por sus desplazamientos y posiciones de patas y cabeza. 


\section{Lámina I}

\section{EL CICLO DIA-NOCHE EN LA CULTURA ATACAMEÑA}

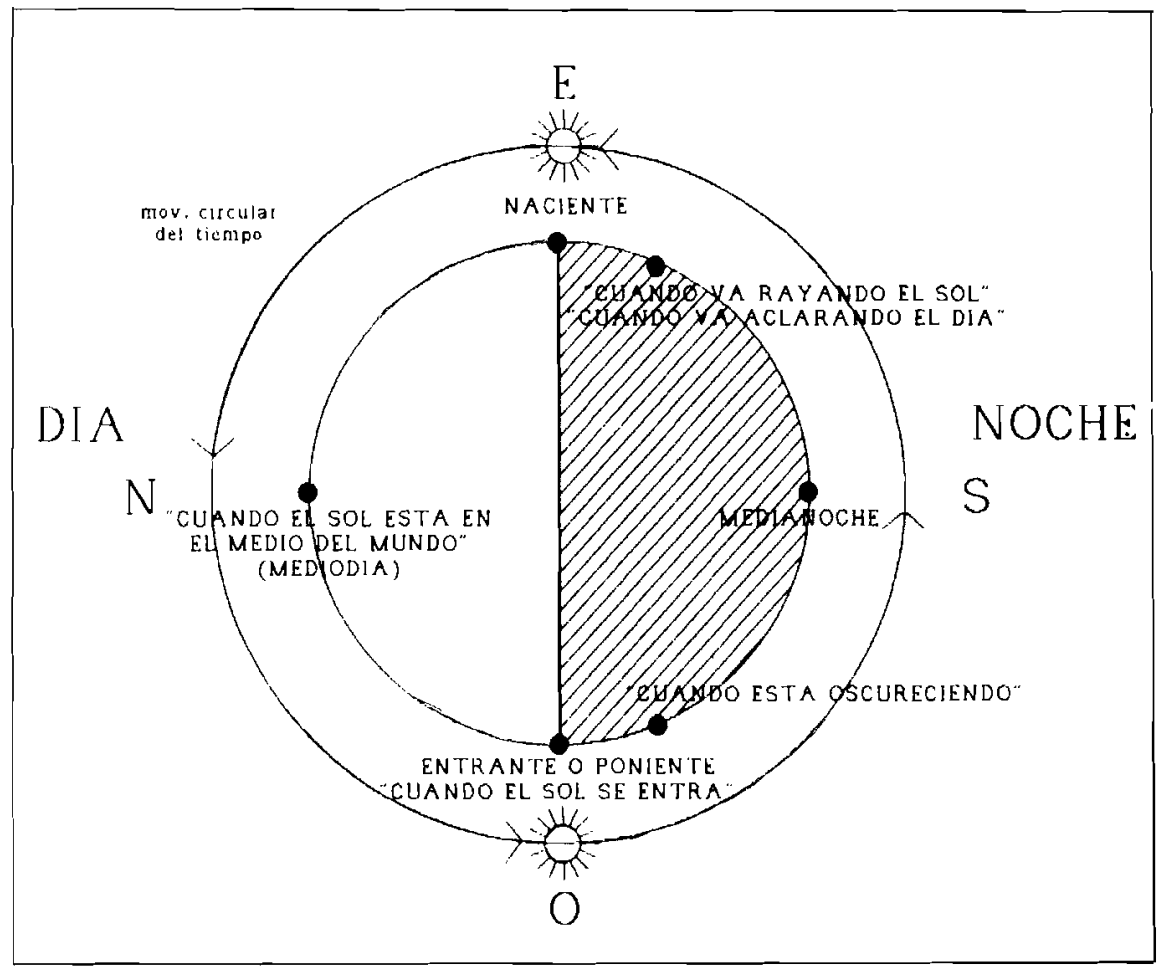

Concepción circular del tiempo atacameño, aún vigente entre los portadores de la cultura tradicional de las aldeas próximas al Salar de Atacama.

La división del tiempo circular en dos mitades, que representan al día y la noche, se asocia a dos ámbitos semánticos opuestos: mientras el día y la luz solar se asocian a "las buenas horas", la noche y su oscuridad (oscurana) se asocian a "las malas horas". Por tanto, al naciente se le asigna principal importancia y connotaciones optimas asociadas con la vida y el bien, por relacionarse con el sol y los espíritus de los cerros. Opuestamente, al entrante o poniente se le asigna connotaciones negativas asociadas a la muerte y los difuntos, al peligro de los espíritus malignos denominados moros y a los accidentes. En suma, el simbolismo temporal atacameño se representa en el círculo del sol -que alberga energías positivas-y en las connotaciones semánticas opuestas de sus dos mitades - el día y la noche-, todo lo cual forma parte de los patrones andinos tradicionales. 


\section{Espacio y movimiento}

Tal como ocurre en otras culturas andinas, como la aymara y la mapuche de Chile, entre los atacameños predomina una orientación espacial hacia el naciente. El Este es el punto cardinal optimo de máxima jerarquía e importancia, centro de gravitación de la concepción espacial, hacia el cual convergen todas las ceremonias rituales y muchas actividades laborales cotidianas, tales como la construcción de eras, siembra y cultivo de melgas y eras. "Se hacen hacia arriba, al naciente, porque de ahí nace el sol. Sale el sol, y el agua también nace de arriba, o sea, de la cordillera... Por eso, el convido (ofrenda-sacrificio) se hace hacia arriba, siempre al naciente, porque todo nace de arriba: la luna, el sol, el agua. Todo". Este testimonio recogido en Socaire explica el significado de esta orientación espacial y, asimismo, su coincidencia con la concepción del tiempo por gravitar ambas hacia el lugar de la salida del sol.

La orientación espacial hacia el Este implica verticalidad, puesto que se dirige "hacia arriba". Dicha verticalidad está presente también en la división del círculo del tiempo en día y noche. Por tanto, es posible inferir una asociación entre verticalidad y vida, y entre horizontalidad y muerte. De hecho, los difuntos se sepultan "abajo" en posición horizontal, con la cabeza hacia el Sur y los pies hacia el Norte. Se detectan una serie de metáforas posicionales espaciales atacameñas que forman parte de los patrones tradicionales del mundo andino. En ellas se manifiesta explícitamente el principio de dualidad:

$\begin{array}{ll}\text { ESTE } & \text { OESTE } \\ \text { arriba } & \text { abajo } \\ \text { vertical } & \text { horizontal } \\ \text { adelante } & \text { atrás } \\ \text { derecha } & \text { izquierda } \\ \text { vida } & \text { muerte } \\ \text { salud } & \text { enfermedad } \\ \text { fuerza } & \text { debilidad } \\ \text { dominio } & \text { dependencia } \\ \text { superioridad } & \text { inferioridad } \\ \text { hombre } & \text { mujer } \\ \text { adulto } & \text { joven } \\ \text { maestro } & \text { discipulo }\end{array}$

Estas dicotomías influyen en la orientación del movimiento en contextos rituales y no rituales. Así, el movimiento circular contra las manecillas del reloj representa a la energía positiva de la vida, reapareciendo con gran frecuencia en los movimientos de las danzas (ruedas) y sahumerios rituales (véase Lam. II); como también en el movimiento del huso en el hilado de la lana (Mostny, 1954, p. 38). Opues- 


\section{Lámina II}

\section{TALATUR DE SOCAIRE}

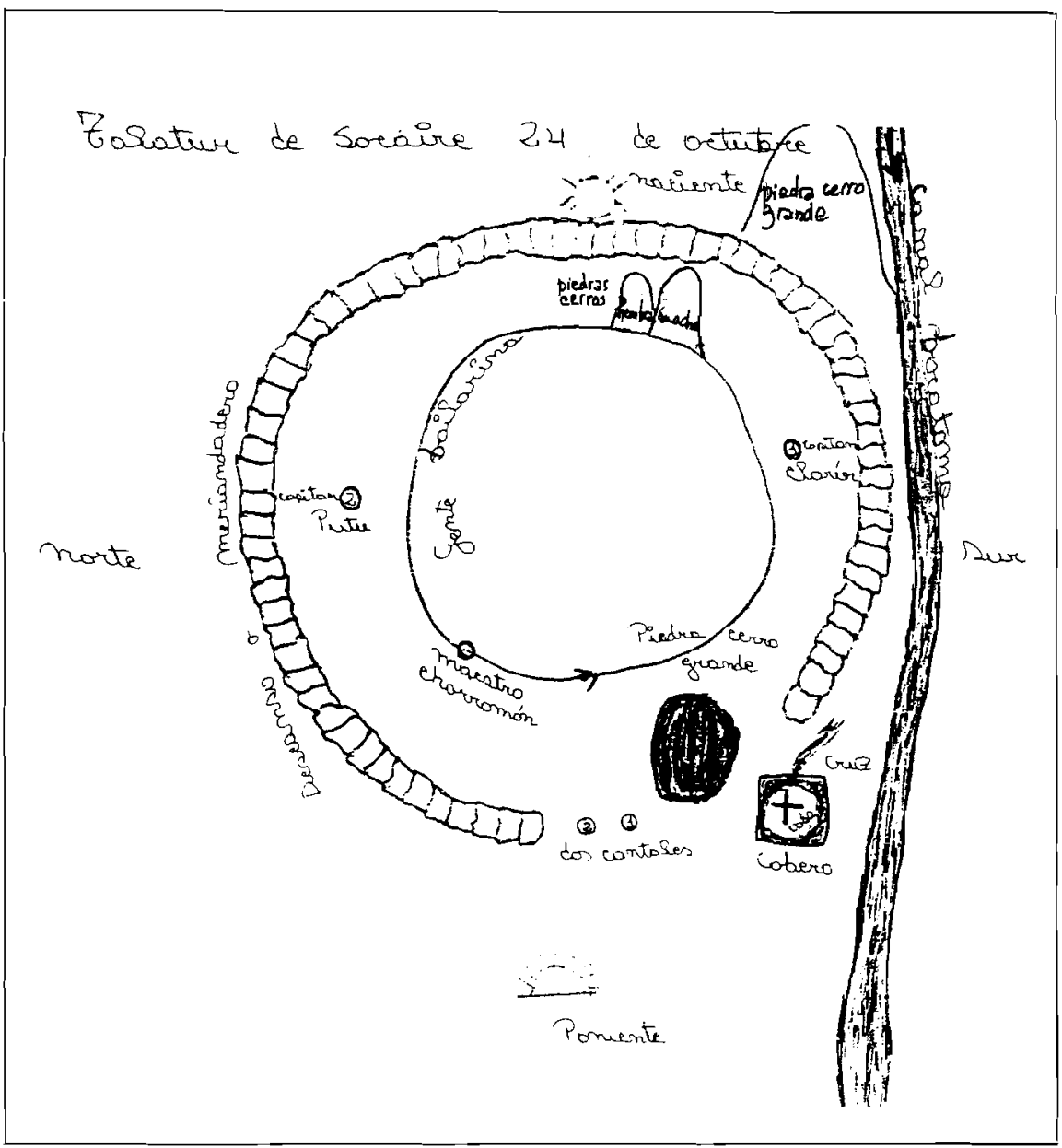

El merendadero de Socaire, lugar sagrado en que se realiza la ceremonia de los cantales en el rito anual de limpieza de canales de regadío. Se observa el círculo de asientos de piedra; el círculo contra las manecillas del reloj de los bailarines y músicos del talatur; el cobero, lugar del sahumerio con coba; y las piedras-cerros que representan simbólicamente a los cerros del lugar. (Dibujo del cantal L. Tejerina.) 
tamente, el movimiento circular a favor de las manecillas del reloj representa a la carencia de energía de la muerte, usándose en el hilado de lana para ajuares fúnebres. En algunas danzas del talatur de Socaire se combinan movimientos circulares en ambas direcciones, generándose círculos en espejo hacia la derecha e izquierda que se reflejan a sí mismos conformando estructuras simétricas. Esto ocurre también en el doble semicírculo de los cerros reactualizado mediante las ofrendassacrificios (kajcher, véase foto 1) y las respectivas invocaciones rituales en la ceremonia de los cantales de Socaire (véase Lám. III); y en la doble rueda - "primera" y "segunda"- del carnaval de Caspana.

En suma, el simbolismo espacial atacameño se manifiesta no solamente en su orientación dominante hacia el Este y en su doble perspectiva vertical y horizontal, sino también en las metáforas posicionales dualistas que forman parte de los patrones tradicionales del mundo andino. A su vez, todo ello influye en la dirección del movimiento y su carga semántica.

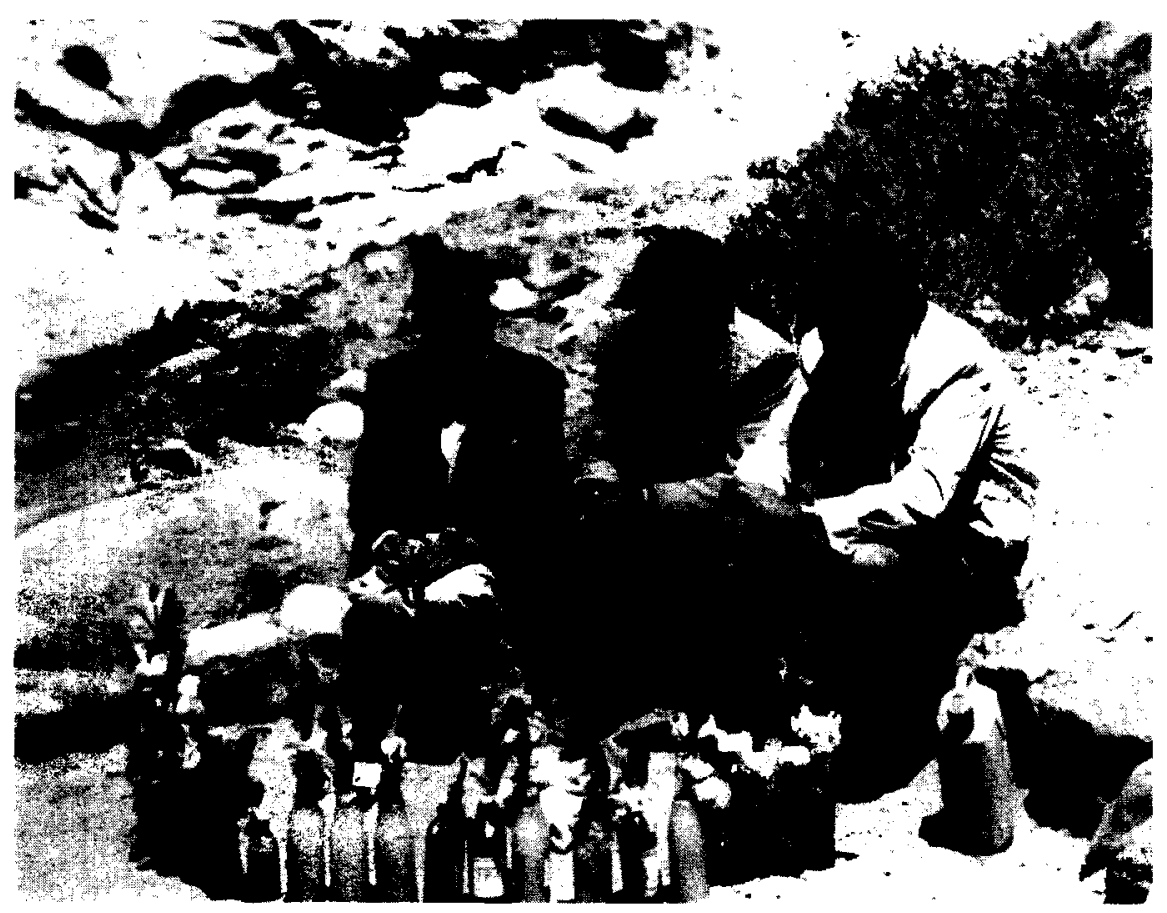

Foto 1: Los tres cantales de Socaire (1988) observando el semicírculo doble de botellas de kajcher, ofrendas ceremoniales destinadas a los espíritus de los cerros y que representan a éstos simbólicamente. 


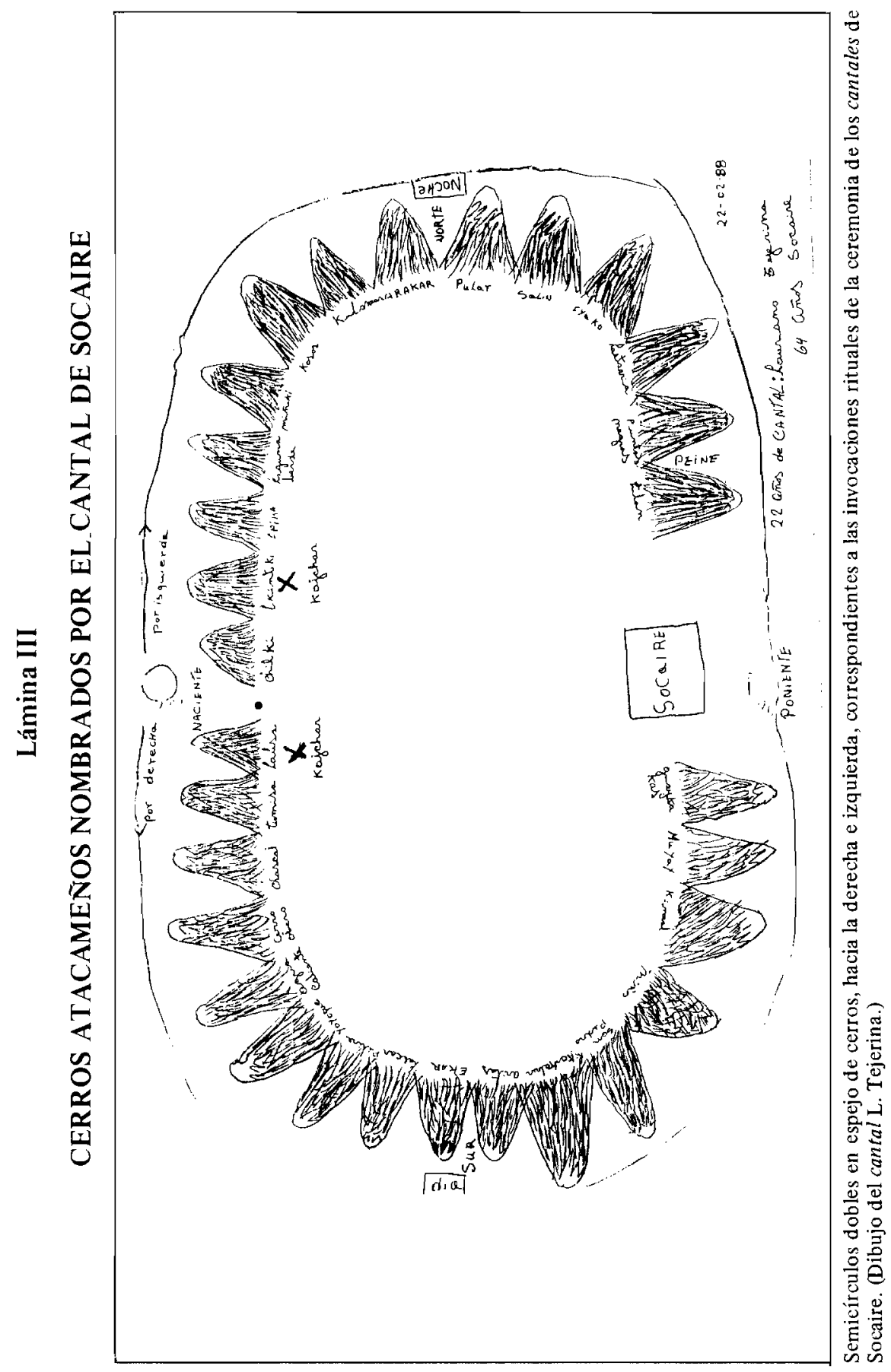




\section{Número}

Como regla general, se consideran buenos los números pares y malos los nones, asociándoseles respectivamente con la buena y mala suerte. Las connotaciones positivas se acentúan si el número par representa a la pareja macho-hembra, simbolizando en este caso a la fertilidad. El número tres se considera malo para iniciar un viaje o un trabajo, tal como siembra u otra actividad agrícola. Otros números nones, tales como el cinco, siete o nueve, aparecen representados en el lazo de difuntos denominado misterio, perteneciente al ajuar funerario del atacameño actual. Como regla general, los nones se asocian con la muerte y la carencia de energía vital.

El chorromón, sonaja de campanas piramidales de metal utilizadas en el rito del talatur, constaba en el pasado de doce u ocho campanas agrupadas en parejas de machos y hembras. No obstante, hoy día es más frecuente la de seis que consta de dos campanas machos de sonido grave, y cuatro campanas hembras de sonido agudo (véase Lám. IV). Es evidente el simbolismo antropomórfico de este instrumento musical ritual que representa a la pareja humana, asimilándose al simbolismo positivo de los números pares. El origen precolombino de estas campanas y su dispersión andina ha sido atestiguado en una monografía anterior (GREBE, 1974, pp. 23-25; véase Lám. V). En la ceremonia de los cantales de Socaire, reaparece por doquier el simbolismo del par: en las parejas de las piedras-cerros macho y hembra; de los cantales mayor y menor; y en la representación de los dos semicírculos de cerros en espejo reactualizados respectivamente por los cantales mayor y menor (véase Lám. III); y, durante la limpieza ritual de los canales de regadio. en la pareja integrada por el capitán y la capitana. Reaparece, asimismo, en la doble rueda del carnaval de Caspana.

En el simbolismo atacameño del par y de la pareja macho-hembra subyacen los principios dominantes de las estructuras simbólicas andinas expresadas en la dualidad, las relaciones simétricas y la bifurcación sexual. Las dos primeras reflejan las preocupaciones centrales del hombre andino por el orden cósmico; y la última representa a la idea básica de fertilidad constituyendo ésta, quizás, una piedra angular del pensamiento andino y sus patrones tradicionales de continuidad. Esta idea de fertilidad se expresa cabalmente en la siguiente frase "el parcito es mejor porque multiplica" (Camar). En la simbología del maíz, que se reactualiza en los carnavales de San Pedro de Atacama, Caspana y otros pueblos atacameños del interior, la fertilidad es representada por las parejas de dos o cuatro pujllai o carnavales, actores rituales denominados también viejo y vieja, que portan matas de maíz con mazorcas maduras (véase Lám. VI). 


\section{Lámina IV}

\section{CHORROMON ATACAMEÑO}

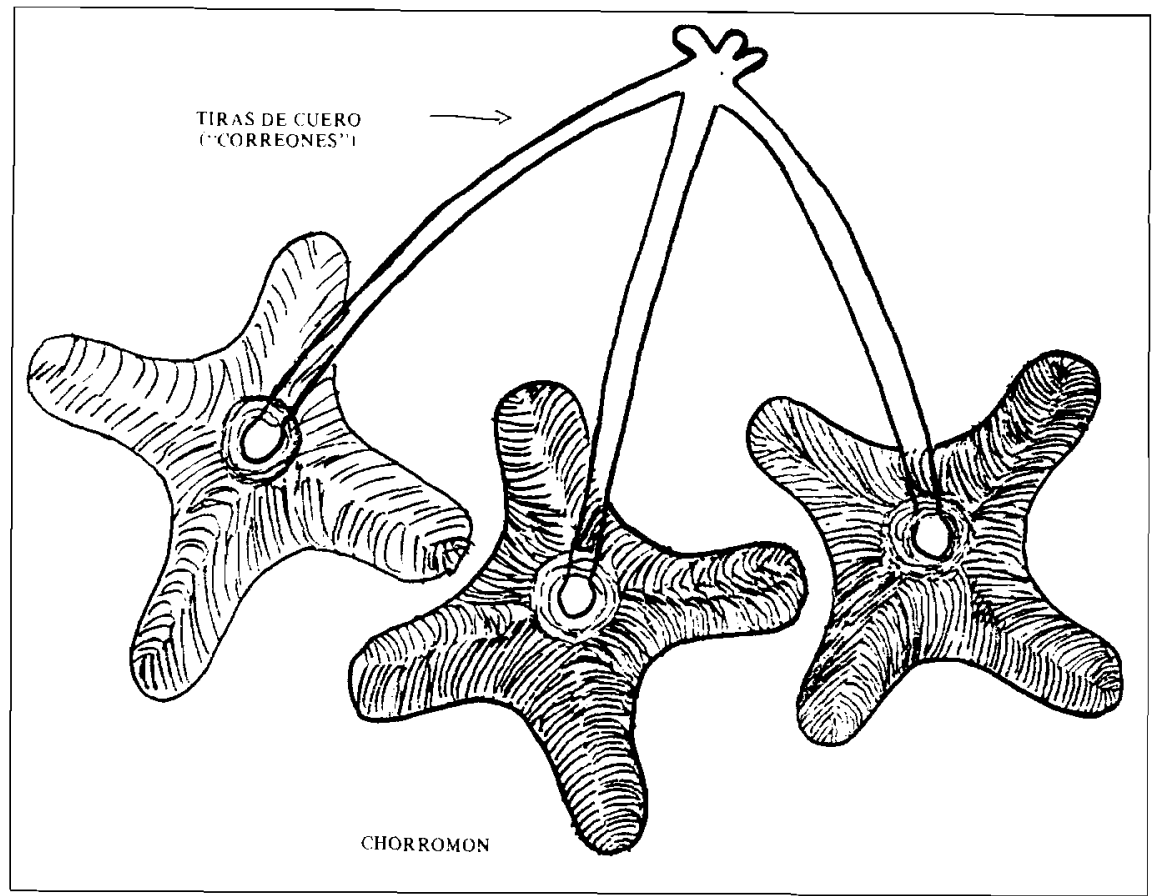

Dibujo de tres campanas piramidales pertenecientes a un chorromón, sonajero de campanas metálicas utilizado en el talatur atacameño diseñado por un músico de Socaire.

\section{Lámina V}

\section{COMPONENTES DEL CHORROMON PRECOLOMBINO}

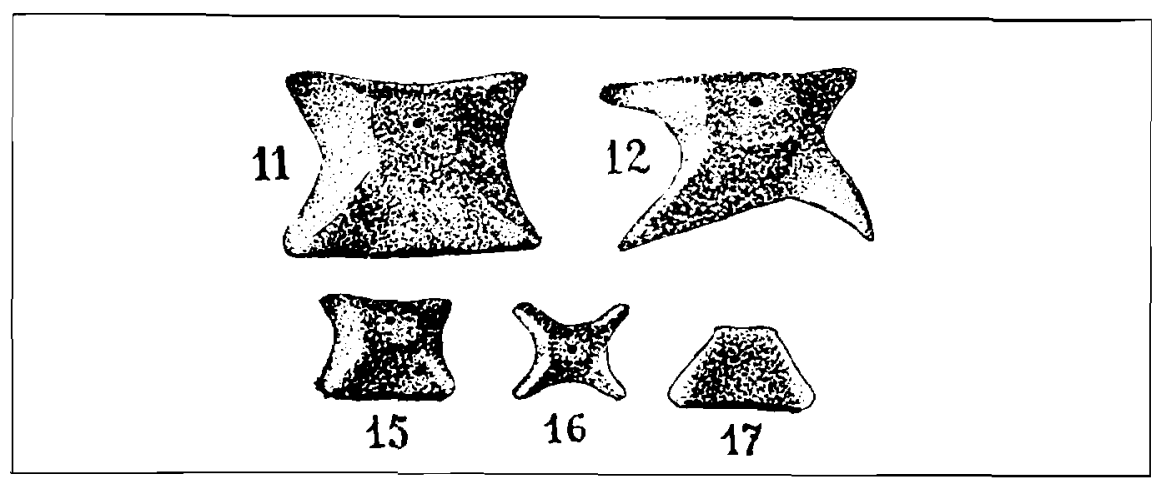

Campanas piramidales de metal pertenecientes a la cultura atacameña precolombina de Chile. (Detalle de la Lam II, publicada en Grebe 1974: 19). 


\section{Lámina VI}

CARNAVALES DE SAN PEDRO DE ATACAMA

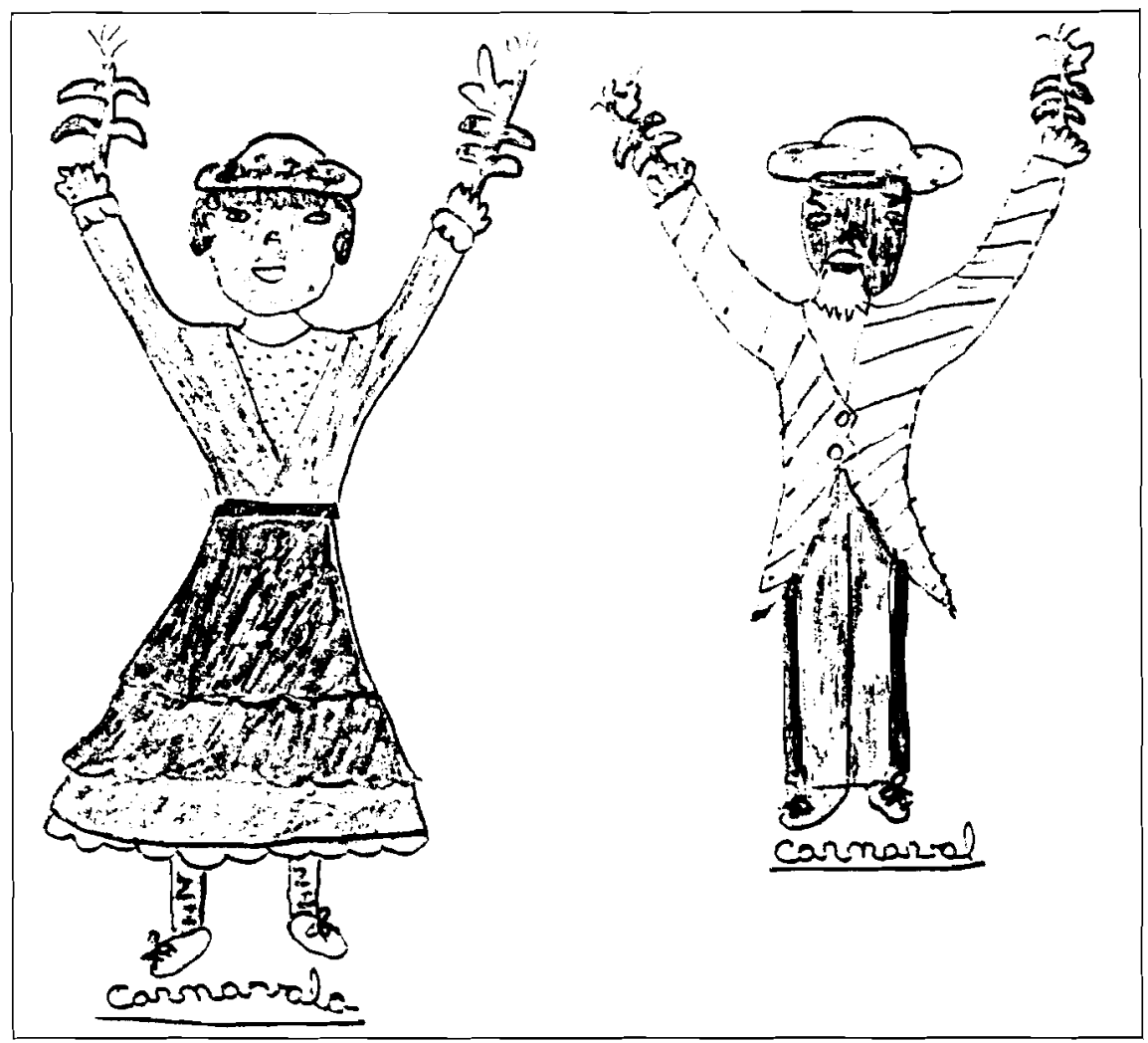

Los dos carnavales o puillai atacameños, portando matas de maíz con mazorcas maduras. (Dibujo infantil.)

\section{Color}

Los atacameños reconocen la importancia ritual de dos grupos de colores, atestiguando sus significados simbólicos respectivos. Existe un estrecho paralelismo con la simbología aymara del color. El primer grupo está integrado por el blanco y los matices de la gama del rojo (rosado, rosa-seco, rojo, solferino, granate), a los cuales se asigna connotaciones positivas, asociándoseles al contex to ritual. El segundo grupo está representado por los colores negro y blanco combinados, que representan a los difuntos y a la muerte.

El blanco es el color de las banderas de carnaval llevadas generalmente por la mujer (carnavala). Se asocia, generalmente al color de la nieve y a la majestad de la cordillera cubierta (Camar, Talabre y 
Socaire). En su ceremonial antiguo, los cantales usaban un koni, tocado de plumas rosadas de flamenco (parina) o bien de avestruz (suri) teñidas de rojo. Posteriormente, este tocado fue reemplazado por un pañuelo blanco que representa a la nieve, que actualmente ha desaparecido. La antigüedad de estos tocados de plumas ha sido atestiguado por Mostny (1967, pp. 134-135), en su estudio de los petroglifos de la cuenca del río Loa, la que los asocia a la parafernalia ritual del chamán en el contexto de sacrificios humanos (véase Lam. VII y VIII). Una variante de estos tocados con plumas de avestruz adheridos como penacho a una máscara ritual es empleada en los carnavales calchaquíes del noroeste argentino (CorTÁzAR, Lam. XII; véase foto 2).

En la ceremonia de los cantales de Socaire, las plumas rosadas de parina reaparecen actualmente en las botellas de kajcher, ofrendas-sacrificios de cada familia destinadas a los espíritus de los cerros (tata-mayllko). Según un antiguo testimonio del cantal Laureano Tejerina, recogido por BARTHEL (p. 31), las plumas blancas representan a los niños, las rosadas a las niñas, las rojas a las mujeres y las negras a los hombres. BARTHEL infiere una relación metonímica del rojo con la menstruación femenina (loc. cit.). El mismo cantal Tejerina ha precisado y reinterpretado recientemente (octubre de 1988) este antiguo

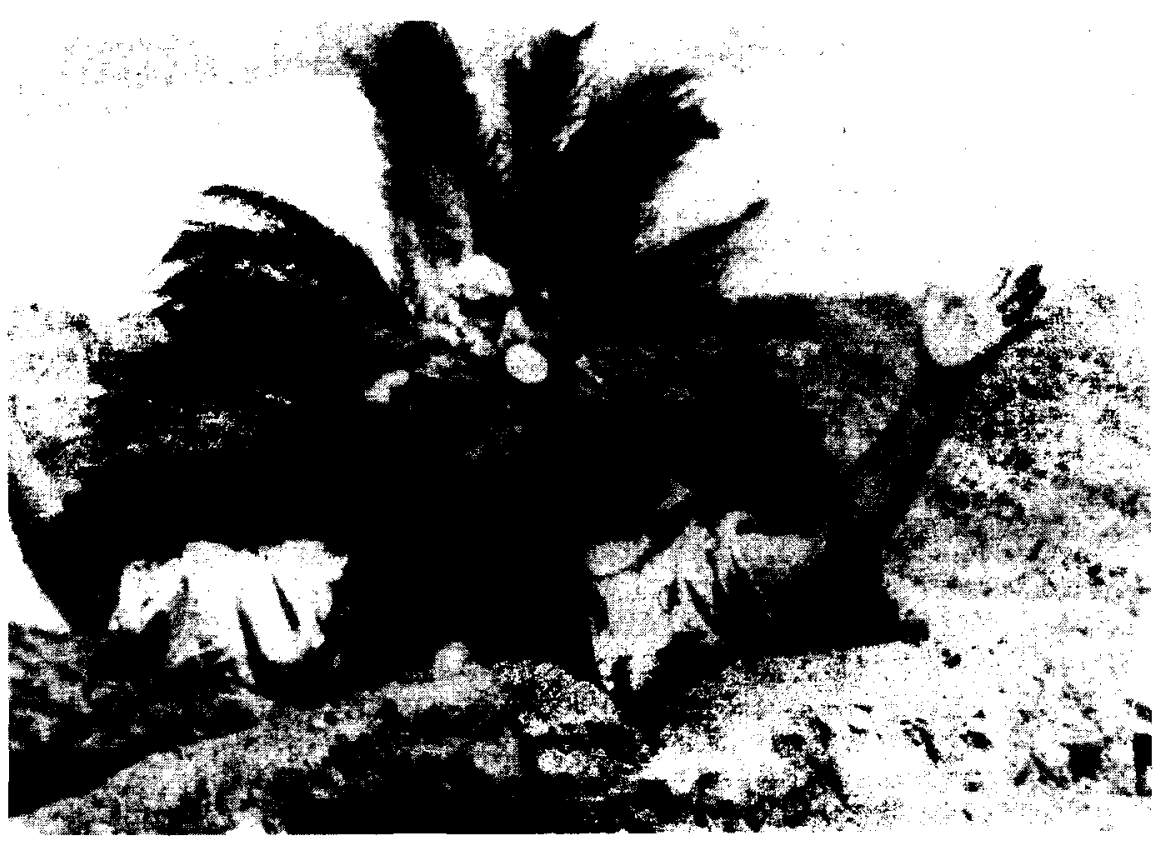

Foto 2: Máscara ritual con penacho de plumas de avestruz del área calchaqui del noroeste argentino (Cortazar 1949: Lam. XII). 


\section{Láminas VII y VIII}

\section{CHAMANES PREHISPANICOS}

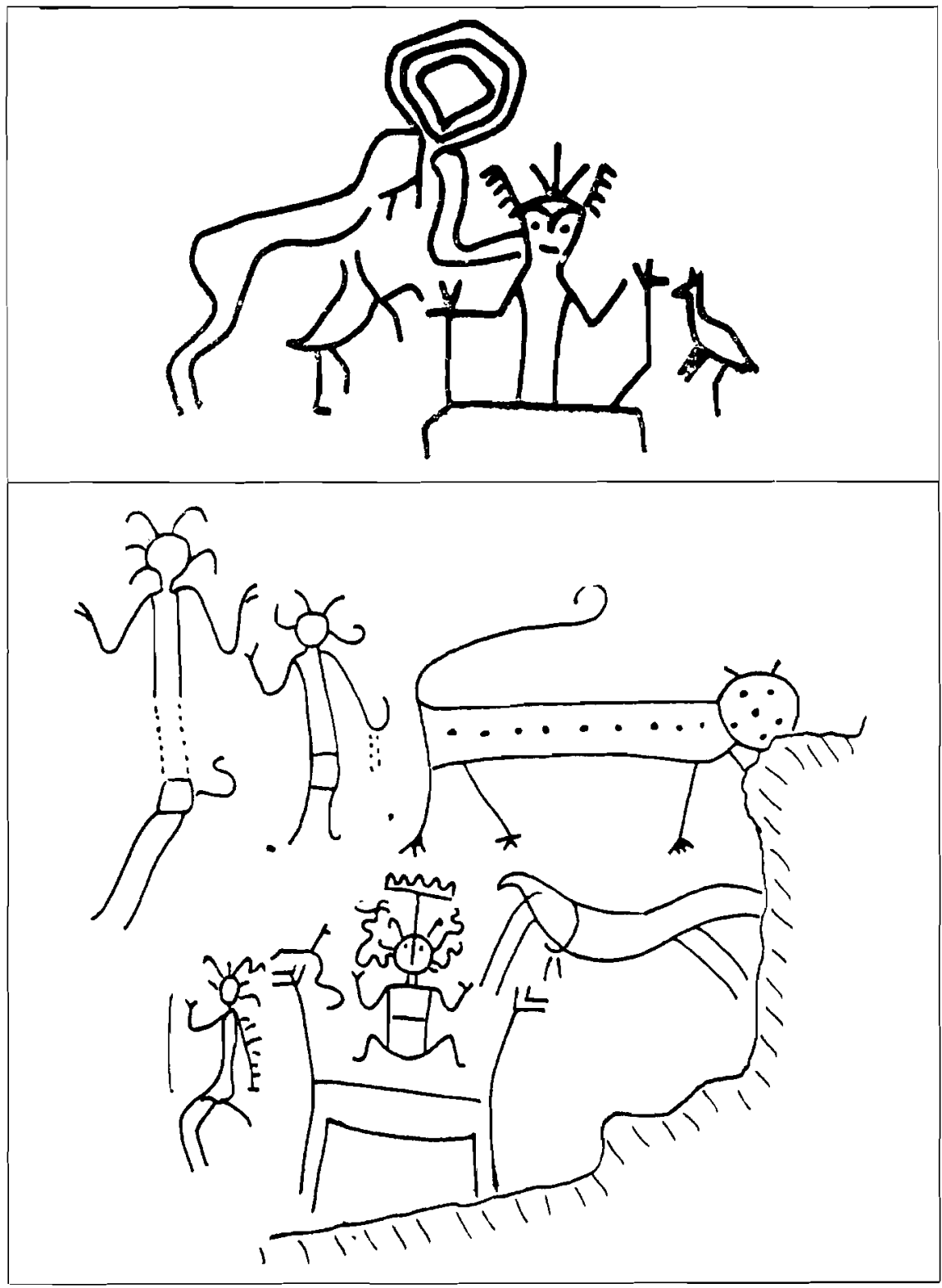

Chamán con tocado de plumas de los petroglifos de la cuenca del Loa (Mostny 1967: 134-135, figs. 9 y 10 ). 
testimonio a la investigadora principal de este trabajo, afirmando que el color de las plumas representa al sexo de cad a uno de los integrantes de un grupo familiar; y que sus respectivos tamaños representan a sus edades. Así, la gama que va desde el blanco al rosado, rojo y granate representa al sexo femenino; y el negro al sexo masculino. Las plumas pequeñas representan a los niños, las medianas a los adultos y las grandes a los ancianos. De esto modo, el penacho de plumas de parina de cada botella de kajcher simboliza a la familia completa que entrega la ofrenda-sacrificio; cada pluma -de acuerdo a su color y tamañosimboliza al sexo y edad de cada uno de sus miembros; y la suma total de botellas de kajcher y sus plumas representa simbólicamente a la comunidad, como un todo. Así, el kajcher es la ofrenda trascendente, sacrificio solemne y expresión de agradecimiento de cada familia a los espíritus del cerro, agua, tierra y antepasados, mediatizado por la acción ritual de los cantales.

He podido observar que el uso profuso del blanco y de las gamas del rojo caracteriza a los carnavales atacameños estudiados recientemente. Por su parte, la combinación del negro y blanco representa simbólicamente a los muertos. Estos colores están presentes en el ajuar funerario de un difunto, a quien se le amarran cordones de lana natural "torcidos al revés". La mezcla de ambos colores se denomina overito, y constituye el luto de la gente antigua: "Es bueno para difuntos, triste para el vivo" (Camar).

\section{I1. Patrones Cognitivo-simbólicos en el mito y Ritual}

\section{Mito}

Según el cantal Horacio Morales, de Peine, para los atacameños "la naturaleza es viva y la tierra es todo. Nosotros creemos que puede ser algo muy superior. Cerro, tierra y nacimiento (las aguadas) son poderes de la naturaleza que tienen fuerza propia". Por otra parte, el señala que los tata-abuelos "son espíritus de la gente antigua", de los antepasados, que también poseen gran poder. En consecuencia, el mundo sobrenatural de los atacameños está presidido por cuatro seres mitológicos principales. Los tres primeros son espíritus de la naturaleza: pachamama -"la santa madre tierra"-, tata-mayllko o tata-cerro -el espíritu del cerro-, y tata-putarajni -el espíritu del agua-. El cuarto consiste en los tata-abuelos, espíritus de los antepasados prehispánicos. Existen, además, otros espiritus menores asociados con fenómenos naturales y culturales. Ellos son: el espíritu del camino, de la apacheta y de la piedra de cantera; de la semilla y de la siembra; del ganado y del tejido a telar. Los atacameños tradicionales aún mantienen una rica interacción con estos espíritus, "como si estuvieran vivos", dialogando con ellos, dedicándoles of rendas denominadas convidos o tinkas. Otro tipo de sacrificios propiciatorios denominados wakis se realizan en los 
ritos de marcación del ganado. Todos ellos constituyen pagos por los beneficios recibidos y por recibir. A los espíritus mayores de la tierra, cerro, agua y antepasados se les suele despertar de sus sueño antes de ciertos rituales. $Y$ si ellos no son tratados con el debido respeto y veneración, pueden golpear o castigar al atacameño con enfermedades.

Pachamama es el espíritu femenino, que representa a la tierra atacameña y a su fertilidad. Es dueña de todos los terrenos, pastizales, campos cultivados y rebaños. Otorga fertilidad a la tierra sembrada y a los animales, permitiendo la producción de una abundante cosecha. Los frutos de la tierra y la multiplicación del ganado no se producirían sin su poder engendrador. Suele representarse en la tierra misma y en los frutos de la cosecha que decoran ciertos objetos rituales. Tal es el caso de la cruz del maíz o calvario, y las mazorcas maduras en manos de los pujllai o carnavales, en San Pedro de Atacama y Caspana (véase Lam. IX). Tata-mayllko es el espíritu de los cerros, montañas y volcanes, quien mora en "todas las alturas". Es dueño de los ojos de agua, vertientes, lluvias y pastizales de sus cumbres, laderas y quebradas. Se le identifica con la forma física y nombre de un cerro o volcán sagrado reconocido en una localidad. Tata-putarajni es el espíritu del agua que reside en vertientes, aguadas, nacimientos, ojos de agua, o canales de regadio prehispanos, con los cuales se le identifica. Es quien proporciona el agua que fertiliza los cultivos y que permite la vida del hombre y su ganado. Se cree que es el agua misma, o bien el esposo del agua. A estos tres espíritus de la naturaleza se les suele invocar en conjunto, puesto que están intimamente vinculados entre si : el cerro origina al agua, y ésta fertiliza a la tiera. En Camar afirman que "va todo junto: mayllko, nacimiento y pachamama".

Por ser espíritus de los antepasados, a los tata-abuelos se les teme por su gran poder y se les respeta por los restos visibles de su obra cultural representada por los canales de riego, las pircas de las eras y las casas de piedra. Se les identifica con estas casas y sus áreas circundantes, consideradas como lugares peligrosos para el pastor y el caminante. En Talabre se dice de los tata-abuelos lo siguiente: "Son bravos esos. Lo miran y lo enferman a uno. Ese es el golpe del abuelo". En Socaire lo confirman: "Estos golpes son de poder. Hay fuerzas y poder en la tierra, cerro, nacimiento y abuelos". Por sus respectivos entornos, se debe transitar con cautela y respeto.

El hombre atacameño interactúa también con otros espíritus menores que se identifican con fenómenos naturales y culturales. Se cree que tanto la piedra como la semilla, tanto el camino y la apacheta como la siembra, el ganado y el tejido de telar poseen espíritu, vida propia y poder. Por esta razón, se da una relación íntima, profunda y respetuosa entre el caminante, su camino y la apacheta; entre el maestro cantero y su piedra; entre el agricultor, su semilla y su terreno cultivado; entre el pastor y su rebaño; entre la tejedora y su tejido.

Cada uno de los seres mitológicos mencionados representa a los fenómenos o entidades con las cuales se identifican. Por tanto, dichos 


\section{Lámina IX \\ CARNAVALES DE CASPANA}

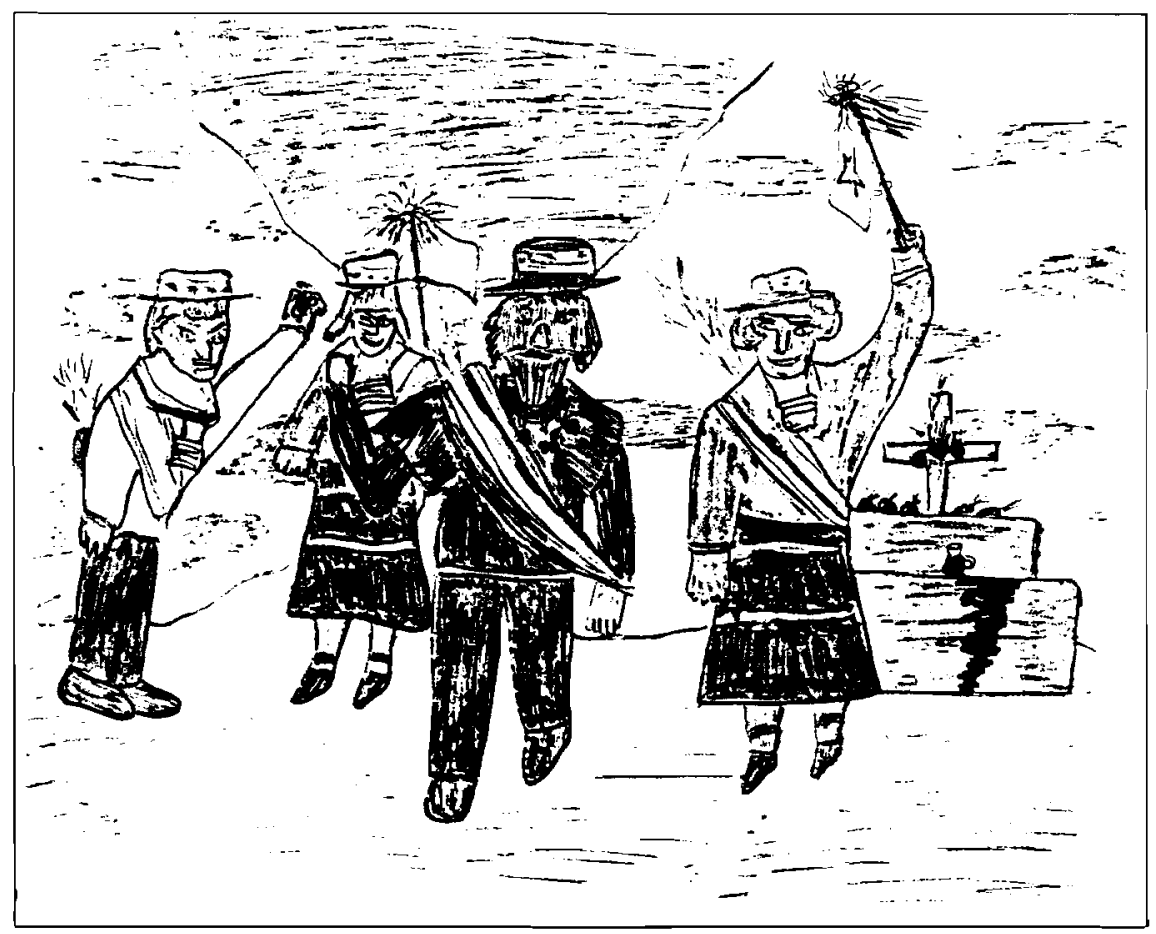

Las dos parejas de carnavales o pujlai de Caspana, portando mazorcas de maíz en la espalda, símbolos de fertilidad, y banderas blancas de carnaval. (Dibujo de un actor ritual.)

espíritus son símbolos que condensan las tramas de significados que, al mismo tiempo, separan y conectan sus dominios semánticos. Operan en un nivel metonímico por relaciones de contigüidad, como entidades abstractas específicas que reemplazan a totalidades concretas.

\section{Ritual}

El conjunto de creencias mitológicas recién descritas es reactualizado en un ciclo compuesto de cuatro ritos: de la semilla o siembra, de la limpieza de canales de regadío (que incluye la ceremonia de los cantales y el talatur), del carnaval y del enfloramiento. Más que describir estos ritos, interesa destacar el simbolismo de ciertos actos o eventos rituales que ocurren, tanto al interior de cada rito, como también fuera de ellos. Dichos actos o eventos rituales son: a) las tinkas o convidos, b) los wakis o sacrificios de animal, c) los sahumerios, y d) el canto del agua. 
a) Las tinkas o convidos son, al mismo tiempo, pago por beneficios recibidos de un espíritu y una ofrenda propiciatoria por nuevos beneficios solicitados. Es una especie de convenio o acuerdo para quedar en buenas relaciones con el espíritu. Deben hacerse con fe y conforme a las normas de la tradición atacameña para evitar un golpe o castigo de este espíritu. La mayor parte de las tinkas son ofrendas de aloja o vino y ulpo de harinas surtidas acompañadas de hojas de coca $y$, ocasionalmente, de algún licor fuerte. Se efectúan con la mano derecha y de acuerdo a un orden espacial prescrito, de derecha a izquierda. Esto se fundamenta como sigue: "Los convidos son por derecha porque de otra manera no recibe el espiritu. Por izquierda es sólo para finaos (difuntos o tata-abuelos) o para luto... Se hace con la mano izquierda porque el finao se murió: ya no tiene fuerza...".

Se destacan a continuación algunos rasgos sobresalientes de estas tinkas o convidos. En el rito de la semilla o siembra, se hace una tinka a pachamama. Para ello, se cava un hoyo en la tierra, colocándose en él primero las hojas de coca, luego la ulpeada elaborada con aloja de algarrobo y harinillas surtidas. Se pide protección a pachamama para la siembra, tapándose luego el hoyo con tierra. En el rito de limpieza de canales de regadío de Peine, se desarrolla la ceremonia de los cantales que incluye convidos al nacimiento del agua (vertiente), arrojándole plumas rosadas de flamenco, ulpo con aloja de algarrobo y coca: ese es el pago por el agua recibida (Mostny, 1954, pp. 90-91). En la versión de Socaire del mismo rito, se hacen ofrendas-sacrificios de kajcher: una botella con aloja de algarrobo adornada con plumas de flamenco, que lleva una bolsita con tuftuka, consistente en harinillas surtidas acompañadas de un trozo de grasa del pecho del llamo, amasadas posteriormente por los cantales. Se ofrecen conjuntamente a tata-mayllko y tata-putarajni, recordando asimismo a pachamama y a los tata-abuelos, incinerando todo en la coba ardiendo, sahumerio efectuado en un lugar especial (cobero) del lugar de culto (merendadero). Se paga así por el agua recibida, nombrando los cerros que dan el agua y pidiendo abundante riego para la nueva siembra y el ganado. Antiguamente, también se incineraba el waki, consistente en figuras pequeñas de animales hechas con tuftuka, dedicado al espíritu del cerro y del agua. Al tata-abuelo se le hace tinka situándose al lado derecho de la puerta de la casita de los tata-abuelos, estructura prehispana de piedra cuyas funciones aún están en estudio (véase foto 3 y Lam. X). Con la mano izquierda, se introduce en su interior hojas de coca, ulpeada y/o aloja de algarrobo, pidiéndole al tata-abuelo que cese sus golpes y agradeciéndole por su trabajo y esfuerzo creativo de su obra, herencia de los atacameños. Al tejido a telar, se le convida hojas de coca para que alcance la lana y termine pronto la tarea sin que se enrede el hilado. Y así, con ligeras variantes, se hacen convidos al ganado, camino, apacheta, piedra y a otras entidades que, según se cree, poseen poder y albergan espíritus. 


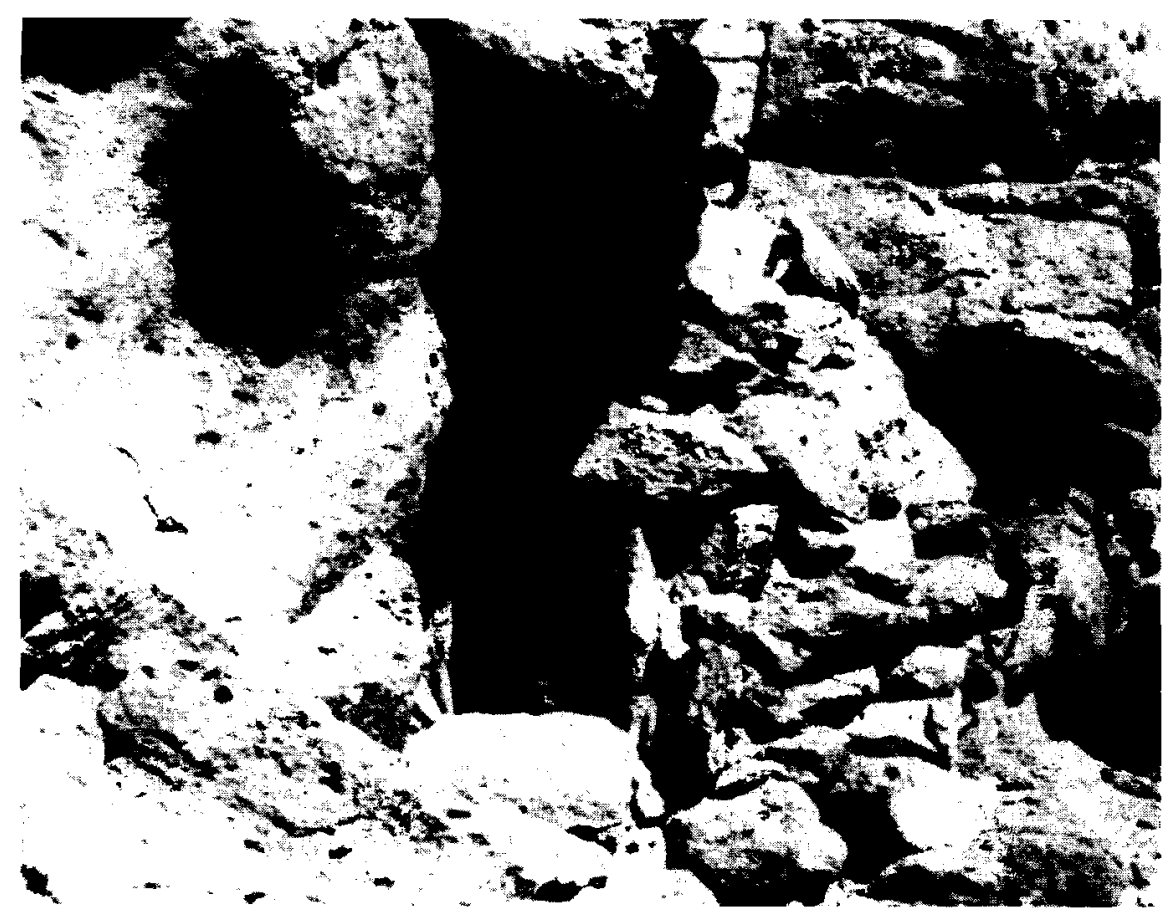

Foto 3: Casas de los tata-abuelos (antepasados prehispánicos) en Socaire. Son estructuras de piedra construidas por el hombre aprovechando aleros rocosos, o bien sobre una base circular de piedras superpuestas similar a un horno.

\section{Lámina $X$}

\section{OFRENDA RITUAL A LOS ANTEPASADOS}

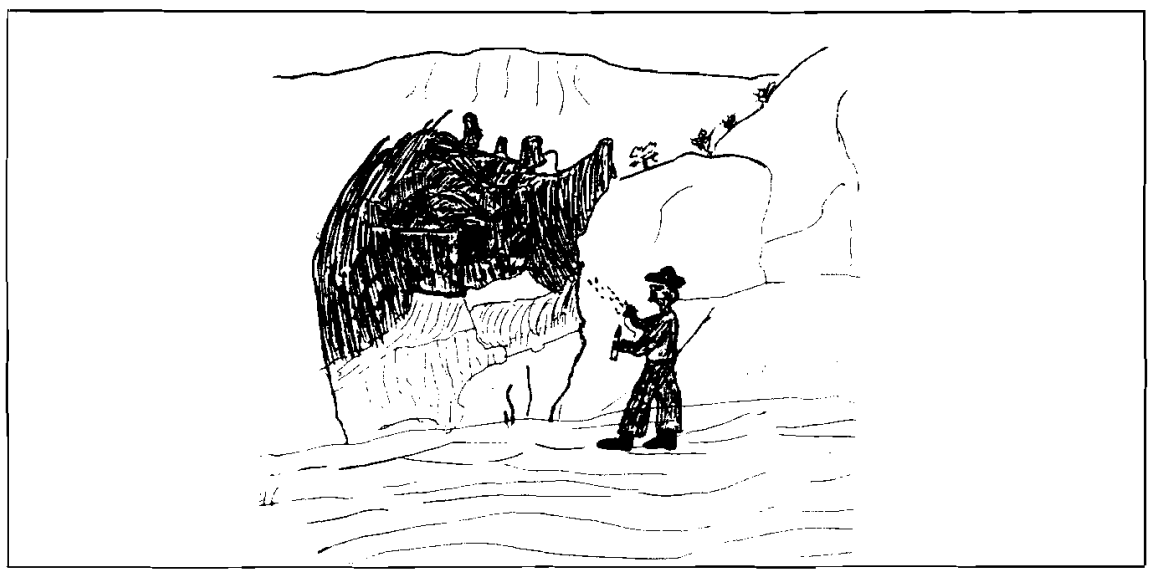

Tinka o convido (ofrenda ritual) dedicada al tata-abuelo (antepasado). El actor ritual se ubica al lado derecho de la estructura prehispánica de piedra, derramando sobre ella y/o en su interior chicha de algarrobo y hojas de coca. (Dibujo de un pastor atacameño de Socaire.) 
b) Los wakis son sacrificios de un animal que se hacen hoy dia, con menor frecuencia, en los enfloramientos de ganado. Luego de preparar un sahumerio dentro del corral, se elige un llamo o cordero macho blanco, el cual se sacrifica fuera del corral. Allí se cava un pequeño hoyo en la tierra, depositando vino y aloja de algarrobo con coca en honor a pachamama y a los cerros, pidiendo protección y multiplicación del ganado. Se procede luego a faenar y cocinar el animal sacrificado. Otro tipo de waki más antiguo deja desangrar al animal sacrificado en el pujio, hoyo situado al centro del corral, ofrendand o la sangre a pachamama y a los cerros (véase Lam. XI).

c) El sahumerio consiste en la incineración de la yerba aromática chacha o coba en el cobero (espacio destinado a la incineración de la $c o b a$ ). Este acto ritual desempeña un papel relevante en la ceremonia de los cantales de Socaire. Por una parte, el humo fragante que despide la coba se transforma en un medio de comunicación simbólico a través del cual llega a los cerros "el sonido de las herramientas" (ruido de la

\section{Lámina XI \\ SAHUMERIO RITUAL}

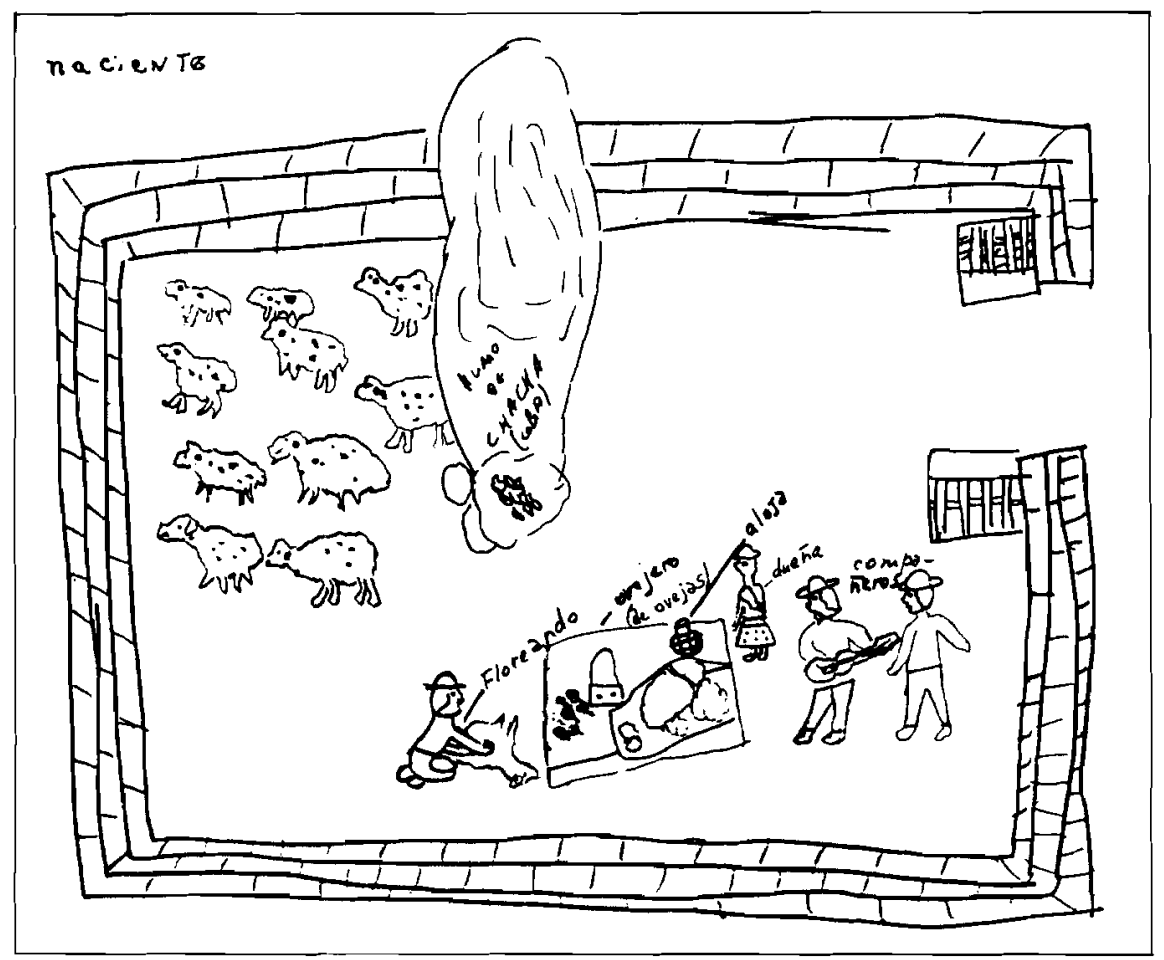

Waki o sacrificio de una oveja en un corral atacameño con ocasión de un enfloramiento de ganado, acompañado de un sahumerio de koba o chacha. (Dibujo de un actor ritual.) 
gente que trabaja en la limpieza de canales de regadío y en la bocatoma). Así, tata-mayllko sabe "que tiene mucha visita". Por otra parte, la coba junto al humo que despide en su incineración se convierte en el idioma mediante el cual se comunica el cantal con ei espíritu del cerro. El humo fragante tiene el poder de transportar no sólo los mensajes implícitos, sino también las ofrendas-sacrificios incinerados.

d) El canto del agua surge, en el contexto ritual de la limpieza de canales, cuando el maestro del talatur enseña a su discipulo a adquirir los conocimientos rituales reservados a dicho oficiante, especializado en música y danza ceremoniales. En dicha ocasión, maestro y discípulo hacen su convido al agua en el rito de limpieza de canales de regadío. Según el testimonio del maestro del talatur de Peine, Silverio Cruz, en ese momento "ellos escuchan una melodía del agua que no se entiende... El maestro escucha. $Y$ después prosigue con el canto del talatur. El agua va corriendo. Se escucha como que el agua está talando (cantando el talatur). Esto ocurre en la víspera de la limpia de canales. Entonces, el agua está con ruido, porque no se siente como canto. Es un ruido especial... Es como si están talando a lo lejos". Otras veces, se oye claramente que tala el agua allí. En suma, el canto del agua es un lenguaje nacido en el mito de tata-putarajni, como una melodía trifónica generada en la naturaleza (Alvarez y Grebe, pp. 26-29). Esta concepción simbólica de la música guarda estrecha relación con el mito del origen de la música aymara (GREBE, $1980 \mathrm{pp}$. 156-169; 1981 pp. 69-73).

\section{RESUMEN Y DISCUSIÓN}

En los patrones cognitivo-simbólicos del tiempo, espacio, movimiento, número y color, se advierte una marcada preferencia por el círculo contra las manecillas del reloj, la orientación espacial hacia el Este, los números pares, el color blanco y la gama del rojo, todos los cuales se comportan como símbolos cargados de connotaciones positivas, vida y energía. A la inversa, el círculo a favor de las manecillas del reloj, los números impares, la mezcla del negro y el blanco que representa al luto, son símbolos negativos relacionados con la muerte y el mal. Debido a sus características netamente andinas, estos rasgos permiten identificar nexos culturales y patrones comunes, compartidos con otras culturas indígenas de Chile y paises limitrofes.

Los mitos atacameños se centran en tres espíritus de la naturaleza - de la tierra, del cerro y del agua-, en espíritus de los antepasados, y en una serie de espíritus menores asociados a fenómenos naturales y culturales -camino, apacheta, piedra, semilla, siembra, ganado, tejido-. Se produce una interacción simbólica entre los atacameños y estos espíritus mediante la ofrenda, el sacrificio, ciertos medios de 
comunicación ritual - tales como el humo de sahumerio y la música del agua - y otros mecanismos que implican un sistema de premio $y$ castigos.

En la reactualización ritual de dichos mitos, se produce un reciclaje, legitimación y validación de éstos a la par que una serie de transformaciones adaptativas. A través de las actividades rituales, los mitos se integran en el proceso de cambio sociocultural en marcha, sin abandonar su relación esencial con los patrones tradicionales andinos de continuidad.

En las creencias y parafernalia ritual subsisten elementos prehispanos pertenecientes, quizás, a grupos de cazadores precerámicos (Mostny, 1967, pp. 134-137; véase Lám. VII y VIII). Tres ejemplos de estos elementos son: el tocado de plumas de parina o de avestruz del chamán u oficiante ritual, la sonaja de campanas piramidales metálicas, y el gato montés o felino hacha-michi, vinculado al espiritu del cerro: "Va con el mayllko". Estos tres elementos, de indudable origen precolombino, poseen una difusión intercultural amplia y evidencian una sorprendente continuidad de sus esencias y núcleos básicos. Es de interés señalar que tocados de plumas, muy similares, reaparecen en las áreas diaguita-calchanqui y mapuche; las campanas piramidales de metal poseen un indudable origen prehispánico, apareciendo en la arqueología del área diaguita-calchaquí, del noroeste argentino y del norte de Chile (Grebe, 1974, pp. 23-25); y el felino posee una amplia dispersión andina (Dillehay, 1978), constituyendo aún hoy día uno de los animales sagrados emblemáticos del pastoreo entre los aymaras altiplánicos de Isluga (GREBE, 1980, pp. 156-158; 1981, pp. 69-71.

Los astros parecen haber servido, por mucho tiempo, como indicadores en el cálculo del tiempo y del espacio. En el contexto de la mitología atacameña, estos astros constituyen una gran familia de divinidades integrada por el sol, la luna, y ciertas estrellas (CASAsSas, pp. 23). El dios inti (sol), que solía presidir el panteón mítico, aún es mencionado por algunos atacameños de los pueblos del interior (Talabre). El mito de pachamama - "la madre-tierra, proveedora de lo necesario para el sustento" - y los cultos de los antepasados y de las apachetas (loc. cit.) parecen poseer gran antigüedad, dando muestras de su perdurabilidad y vigencia actuales (loc. cit.).

Los atacameños revelan poseer una gran sensibilidad artística y talento para las representaciones visuales, cuya incentivación podría producir en el futuro testimonios útiles en la comparación intra e intercultural.

En suma, concluimos que los hallazgos de la presente investigación indicarían, muy probablemente, la presencia de patrones cognitivo-simbólicos tradicionales de continuidad que poseen roles aglutinantes y una difusión cultural significativa. Estos patrones podrían permitir el establecimiento de conexiones interculturales e intraculturales entre pasado y presente, entre culturas vecinas y lejanas. 
Surgen las siguientes interrogantes: ¿Hasta qué punto dichos patrones tradicionales reflejan la influencia del medio ambiente físico andino? ¿Es posible considerar la posibilidad de que sean productos de corrientes de difusión cultural tempranas o tardías? ¿Cómo influyen los universales culturales en la persistencia de estos patrones analógicos? ¿Es posible explicar cómo y porqué se han mantenido estos patrones, a pesar de la pérdida casi total del kunza como lengua nativa?

Estas interrogantes deben ser respondidas mediante un análisis prolijo de una variada gama de problemas teóricos que exige la maduración de una perspectiva antropológica interdisciplinaria - -etnológica, etnohistórica y arqueológica- tanto del área andina en general, como del área atacameña en particular. La fase en que se encuentra nuestro trabajo etnográfico, como también la extensión limitada asignada a la publicación de sus resultados, impiden, por el momento, un análisis y discusión de estas interrogantes. Nos limitaremos a una sola de ellas, eligiendo la última:

Al haber perdido los atacameños su lengua kunza en el transcurso del siglo XIX, podría ponerse en duda la continuidad de su cultura indigena. Las expectativas se inclinarían hacia una supuesta asimilación de esta cultura ind ígena a un campesinado de ancestro ind ígena. Esta posición descansa en un determinismo lingü ístico asociado a una posición reduccionista, ambos discutibles. Se ha afirmado que el lenguaje constituye una base fundamental sobre la cual descansa la cultura, proporcionando un conjunto de reglas que permiten codificar los conocimientos disponibles sobre el mundo y la conducta social. Sapir y Whorf han señalado que los patrones del lenguaje son fundamentalrs para comprender la ordenación de una realidad cultural. Si aceptásemos la proposición que el lenguaje determina el pensamiento, y éste la memoria de reconocimiento, la cual a su vez opera en las ordenaciones del mundo, sería posible inferir: primero, que las culturas son distintas meramente porque sus lenguajes lo son; $y$, segundo, que la pérdida de un lenguaje nativo determinaría la pérdida de la cultura respectiva. No obstante, el caso atacameño que estudiamos pareceria poner en duda tales proposiciones. Sus patrones cognitivo-simbólicos tradicionales de continuidad sobreviven más allá de las fronteras de sus respectivos lenguajes nativos. Por lo tanto, dichos patrones parecerían darse en niveles supralingüisticos.

Por mucho tiempo, la región atacameña ha sido un espacio de tránsito y de encuentro entre culturas, lo cual parece haber repercutido en un uso paralelo de cuatro lenguas. Aún hoy día, ellos afirman: "Estamos metidos en quichua, aymara, kunza y español" (Talabre). Los resultados del presente trabajo evidencian la innegable preservación de patrones cognitivo-simbólicos tradicionales, que dan lugar a la continuidad cultural, demostrándose asimismo que los atacameños han traducido, transformado, simplificado o sustituido parte de su antigua cultura vernácula. No la han perdido. 


\section{REFERENCIAS}

Alvarez, Cristina y M. Ester Grebe. "La trifonía atacameña y sus perspectivas in terculturales". Revista Musical Chilena, XXVIII, 126-127, 1974, pp. 21-46.

Barthel, Thomas. "Ein Frühlingsfest der Atacameños". Zeitschrift für Ethnologie, LXXXIV, 1959, pp. 24-45.

Bastien, Joseph. "A Shamanistic Curing Ritual of the Aymara: Roles of Traditional and Modern Practitioners in Conflict". Trabajo presentado en el $46^{\circ}$ Congreso Internacional de Americanistas, Amsterdam, 1988.

Casassas, José María. La Región A tacameña en el Siglo XVII [resumen]. Madrid, Facultad de Filosofía y Letras, Sección Historia, Tesis Doctoral, 1970.

Cortázar, Augusto Raúl. El Carnaval en el Folklore Calchaqui, Buenos Aires, Sudamericana, 1949.

Dillehay, Tom D. "Sobre la interpretación del símbolo del motivo del jaguar" Valdivia, Universidad Austral, M.S., 1978.

Grebe, M. Ester. "Instrumentos musicales precolombinos de Chile". Revista Musical Chilena, XXVIII, 128, 1974, pp. 5-55.

Grebe, M. Ester. Generative Models, Symbolic Structures, and Acculturation in the Panpipe Music of the Aymara of Tarapaca, Chile. Belfast, The Queen's University of Belfast, Tesis Doctoral, 2 vols., 1980.

Grebe, M. Ester. "Cosmovisión Aymara". Revista de Santiago (Museo Nacional Vicuña Mackenna, Santiago), 1, 1981, pp. 61-79.

Grebe, M. Ester. "Reflexiones antropológicas sobre temporalidad". Lenguas Modernas, 14, 1987a, pp. 163-172.

Grebe, M. Ester. "La concepción del tiempo en la cultura mapuche". Revista Chilena de Antropologia, 6, 1987b, pp. 59-74.

Leach, Edmund. Culture and Communication: The Logic by Which Symbols are Connected. Cambridge, Cambridge' University Press, 1976.

Mostny, Grete et al.: Peine, un Pueblo A tacameño. Santiago, Instituto de Geografía, Facultad de Filosofía, Universidad de Chile, 1954.

Mostny, Grete. "Ideas Mágico-Religiosas de los “Atacamas"”. Boletin del Museo Nacional de Historia Natural, Tomo XXX, 1967, pp. 129-145.

Sapir, Edward. "Selected Writings of Edwards Sapir". En D.G. Mandelbaum ed., Language, Culture and Personality, Berkeley, University of California Press, 1949.

Spradley, James P. "The Ethnographic Interview. New York, Holt, Rinehart and Winston, 1979.

Turner, Víctor. "Symbols in African Ritual". En J.L. Dolgin, D.S. Kemnitzer y D.M. Schneider eds., Symbolic Anthropology, New York, Columbia University Press, 1977, pp. 183-194.

Whorf, Benjamín L. Lenguaje, Thought and Reality: Selected Writings of B.L. Whorf. Cambridge, Mass., MIT Press, 1956. 